\title{
Pengaruh Pemberian Probiotik Berbeda dalam Sistem Akuaponik terhadap Kualitas Air pada Budidaya Ikan Lele (Clarias sp.)
}

\section{Effect Addition of Different Probiotic in Aquaponic Systems towards Water Quality in Aquaculture Catfish (Clarias sp.)}

\author{
Willy Dhika Pratama ${ }^{1^{*}}$, Prayogo $^{2}$, dan Abdul Manan ${ }^{2}$ \\ ${ }^{1}$ Budidaya Perairan, Fakultas Perikanan dan Kelautan Universitas Airlangga, Surabaya 60115 \\ ${ }^{2}$ Departemen Manajemen Kesehatan Ikan dan Budidaya Perairan, Fakultas Perikanan dan Kelautan Universitas \\ Airlangga, Surabaya 60115 \\ *willy.dhika-12@fpk.unair.ac.id
}

\begin{abstract}
Abstrak
Ikan lele (Clarias sp.) merupakan jenis ikan konsumsi yang memiliki prospek menjanjikan karena mempunyai tingkat serapan pasar cukup tinggi. Permintaaan pasar yang tinggi tersebut memotivasi pembudidaya mengembangkan teknologi budidaya akuaponik. Akuaponik pada prinsipnya disamping menghemat penggunaan lahan dan air juga meningkatkan efisiensi usaha melalui pemanfaatan unsur hara dari sisa pakan dan metabolisme ikan untuk tanaman. Budidaya ikan dengan padat tebar tinggi menyebabkan penurunan kualitas air karena adanya penumpukan bahan organik Penumpukan bahan organik tersebut menyebabkan racun pada perairan karena terdapat amonia (NH3) dan nitrit (N02) pada perairan. Ambang batas kandungan amonia untuk ikan lele yaitu $<0,8 \mathrm{mg} / \mathrm{L}$. Salah satu alternatif dalam mengatasi masalah kualitas air dalam akuakultur yaitu penambahan probiotik. Probiotik mengandung beberapa jenis mikroorganisme yang dapat membantu proses penguraian amonia sebagai agen bioremediasi untuk pengendalian kualitas air. Tujuan dari penelitian ini adalah untuk mengetahui pengaruh pemberian probiotik berbeda dalam sistem akuaponik terhadap kualitas air. Penelitian ini menggunakan metode eksperimental dengan Rancangan Acak Lengkap (RAL), terdiri atas empat perlakuan dan lima kali ulangan yaitu P0 (kontrol), P1 (probiotik A), P2 (probiotik B) dan P3 (probiotik C). Analisis data diolah dengan menggunakan Analysis of Variance. Bila terdapat pengaruh perbedaan maka dilanjutkan Uji Jarak Berganda Duncan. Hasil penelitian menunjukkan bahwa pemberian probiotik dalam sistem akuaponik berbeda nyata $(\mathrm{p}<0,05)$. Dari hasil penelitian disimpulkan bahwa pemberian probiotik dalam sistem akuaponik berpengaruh terhadap kualitas air. Berdasarkan hasil uji statistik menunjukkan bahwa kadar amonia, nitrit dan nitrat terendah terdapat pada perlakuan P2 yaitu $0,0204 \mathrm{mg} / \mathrm{L}, 0,012 \mathrm{mg} / \mathrm{L}$ dan 2,731 mg/L. Kadar amonia, nitrit dan nitrat tertinggi terdapat pada perlakuan P0 (kontrol) yaitu 0,273 mg/L, 0,019 mg/L, 4,218 mg/L.
\end{abstract}

Kata Kunci : Akuaponik, Ikan Lele, Probiotik, Amonia, Nitrit, Nitrat, Clarias sp.

\begin{abstract}
Catfish (Clarias sp.) is a type of consumption fish have promising prospects because it has a high enough degree of market uptake. The high market demand which motivated farmers to develop farming aquaponics technologies. Aquaponics, in principle, in addition to conserve land and water use also increases business efficiency through the utilization of nutrients from food remains and fish for plant metabolism. Fish farming with high stocking density causes a decrease in water quality due to the accumulation of organic matter buildup of organic materials causing toxins in the water because there is ammonia (NH3) and nitrite (NO2) on the water. The threshold for catfish ammonia content is $<0.8 \mathrm{mg} / \mathrm{L}$. Alternative to overcome the problem of water quality in aquaculture is the addition of probiotic. Probiotic contain several types of microorganisms that can help the process of decomposition of ammonia as a bioremediation agent for water quality control. The purpose of this research is to determine the effect of different probiotics in the aquaponics system to water quality. The method that used in this research is experimental with completely randomized design (four treat and five repeated) are P0 (control), P1 (probiotic A), P2 (probiotic B) and P3 (probiotic C). Analysis of data processed using Analysis of Variance. If there are significant differences then continued Duncan's Multiple Range Test. The results showed that the giving of probiotics in the aquaponic system is significantly different ( $p<0.05)$. The final conclusion is that the addition of probiotic in the aquaponic system affect the water quality. Based on the results of statistical analysis showed that the levels of ammonia, nitrite and nitrate was lowest for the treatment of P2 is $0.0204 \mathrm{mg} / \mathrm{L}, 0.012$ $\mathrm{mg} / \mathrm{L}$ and $2.731 \mathrm{mg} / \mathrm{L}$. Ammonia, nitrite and nitrate is highest at PO treatment (control) is $0.273 \mathrm{mg} / \mathrm{L}, 0.019 \mathrm{mg}$ $/ L, 4.218 \mathrm{mg} / \mathrm{L}$.
\end{abstract}

Keywords : Aquaponic, Catfish, Probiotic, Ammonia, Nitrite, Nitrate, Clarias sp. 


\section{PENDAHULUAN}

Ikan lele (Clarias sp.) merupakan salah satu spesies ikan air tawar yang banyak dibudidayakan di Indonesia. Ikan lele merupakan komuditas unggulan air tawar yang sangat populer di masyarakat. Ikan lele memiliki keunggulan dibandingkan dengan ikan lain yaitu pertumbuhannya lebih cepat, harga ekonomis dan kandungan gizi yang tinggi (Mahyuddin, 2008). Ikan lele merupakan jenis ikan konsumsi yang memiliki prospek menjanjikan karena mempunyai tingkat serapan pasar cukup tinggi. Perkembangan produksi ikan lele selama lima tahun terakhir menunjukkan hasil yang signifikan yaitu jumlah produksi dari tahun 2010 sebesar 270.600 ton meningkat menjadi 900.000 ton pada tahun 2014 (Direktorat Jenderal Perikanan Budidaya, 2014).

Permintaan pasar yang tinggi terhadap ikan lele menyebabkan produksi ikan lele meningkat. Untuk memenuhi kebutuhan pasar yang tinggi tersebut pembudidaya mengembangkan teknologi budidaya akuaponik. Teknologi akuaponik terbukti mampu memproduksi ikan secara optimal dengan padat tebar tinggi pada lahan sempit dan sumber air terbatas (Diver, 2006). Akuaponik pada prinsipnya disamping menghemat penggunaan lahan dan air juga meningkatkan efisiensi usaha melalui pemanfaatan unsur hara dari sisa pakan dan metabolisme ikan untuk tanaman
(Ahmad, 2007). Budidaya akuaponik dicirikan dengan kepadatan ikan yang tinggi dan menerapkan sistem resirkulasi (Harahap, 2010).

Budidaya ikan dengan padat tebar tinggi menyebabkan penurunan kualitas air karena adanya penumpukan bahan organik (Aquarista dkk., 2012). Penumpukan bahan organik tersebut menyebabkan racun pada perairan karena terdapat amonia (NH3) dan nitrit (N02) pada perairan. Amonia biasanya timbul akibat feses organisme dan aktifitas jasad renik dalam proses dekompsisi bahan organik. Keberadaan amonia mempengaruhi pertumbuhan ikan karena mengganggu proses osmoregulasi dan mengakibatkan kerusakan fisik pada jaringan. Ambang batas kandungan amonia untuk ikan lele yaitu $<0,8 \mathrm{mg} / \mathrm{L}$ (BBPBAT, 2005). Salah satu alternatif dalam mengatasi masalah kualitas air dalam akuakultur yaitu penambahan probiotik. Probiotik mengandung beberapa jenis mikroorganisme yang dapat membantu proses penguraian amonia sebagai agen bioremediasi untuk pengendalian kualitas air. Beberapa mikroorganisme yang terkadung dalam probiotik tersebut adalah Nitrosomonas dan Nitrobacter merupakan bahan yang cocok ditambahkan dalam media pemeliharaan ikan dengan tujuan meningkatkan penguraian amonia (Tambunan, 2010). Berdasarkan penjelasan di atas, perlu dilakukan penelitian untuk 
mengetahui probiotik mana yang terbaik dalam menguraikan amonia di media budidaya ikan lele pada sistem akuaponik.

\section{MATERI DAN METODE}

\section{Tempat dan Waktu Penelitian}

Penelitian ini telah dilaksanakan pada tanggal 28 Mei sampai 27 Juni 2016 di Laboratorium Pendidikan Fakultas Perikanan dan Kelautan, Universitas Airlangga, Surabaya.

\section{Alat dan Bahan}

Peralatan yang digunakan pada penelitian ini meliputi bak plastik tempat pemeliharaan ikan, pompa air, pipa pvc 2,5 inci, selang, net pot, timbangan digital, jaring, penggaris, gelas ukur, $\mathrm{pH}$ meter, termometer, DO meter, gelas ukur, labu ukur, erlenmeyer, pipet ukur, pipet volumetrik, spatula kaca, kuvet dan spektrofotometer.

Benih ikan lele yang digunakan berukuran 5-7 cm sebanyak 2.000 ekor. Setiap bak berisi 100 ekor ikan lele, Tanaman yang digunakan adalah kangkung air yang disemai selama 1-2 minggu pada media tanam rockwool sebagai tempat tumbuh dan merekatnya akar tanaman. Probiotik komersil A dengan merk EM4 (Lactobacillus casei, Saccharomyces cerevisiae), probiotik komersil B dengan merk Petro Fish (Lactobacillus, Nitrosomonas, Bacillus) dan probiotik komersil C dengan merk Boster (Nitrosomonas, Nitrobacter, Bacillus), bahan uji amonia (Fenol, Natrium Klorida, Natrium nitroprusid, Trinatrium sitrat, $\mathrm{NaOH}$, Natrium hipoklorit, akuades) dan bahan uji nitrat (KNO3, $\mathrm{HCl}$, Akuades).

\section{Prosedur Penelitian}

Persiapan penelitian dengan membersihkan peralatan yang akan digunakan. Peralatan yang digunakan berupa bak plastik ukuran $54 \times 32 \times 29 \mathrm{~cm}^{3}$, tempat pemeliharaan ikan yang disterilisasi menggunakan chlorine dengan dosis 1,5 ppm yang disebar merata ke dalam air, selanjutnya dikeringkan selama satu hari. Bak plastik yang sudah kering diisi dengan air tawar. Benih ikan lele yang digunakan berukuran 5-7 $\mathrm{cm}$. Sebelum ditebar pada media pemeliharaan benih ikan diaklimatisasi terlebih dahulu agar suhu air media selama pengangkutan benih dengan air media pada wadah pemeliharaan sama. Benih ikan lele kemudian dimasukkan ke dalam bak pemeliharaan dengan padat tebar 2.000 ekor $/ \mathrm{m}^{3}$ sehingga dalam satu bak plastik dengan volume 50 liter dapat ditebar 100 ekor ikan lele.

Merancang sistem akuaponik yang terdiri dari pipa pvc berukuran 2,5 inci dan pompa air sehingga terbentuk sistem resirkulasi. Tanaman kangkung harus disemai terlebih dahulu pada media rockwool, setelah tumbuh baru dipindahkan 
dalam net pot. Waktu persemaian kurang lebih 12-14 hari. Jumlah tanaman kangkung yang digunakan adalah 30 batang/bak.

Pemeliharaan ikan lele dilakukan dengan pemberian pakan komersial berupa pellet yang diberikan tiga kali sehari pada pukul 08.00 pagi, 12.00 siang dan 16.00 sore. Pakan yang diberikan sejumlah 5\% dari berat tubuh ikan. Satu minggu setelah pemeliharaan ikan lele dilakukan penambah probiotik dalam media budidaya sebanyak $0,25 \mathrm{ml} / \mathrm{L}$ atau $12,5 \mathrm{ml} / \mathrm{bak}$. Pemberian probiotik selanjutnya dilakukan setiap satu minggu sekali.

Pengambilan sampel air untuk pengukuran amonia, nitrit dan nitrat dilakukan pada awal setelah ikan lele di tebar, selanjutnya dilakukan pengukuran kembali setiap tiga hari sekali untuk mengetahui fluktuasi amonia, nitrit dan nitrat dalam media pemeliharaan. Pengukuran amonia, nitrit dan nitrat menggunakan spektrofotometer. Pengukuran suhu menggunakan termometer, $\mathrm{pH}$ menggunakan $\mathrm{pH}$ meter, DO menggunakan DO meter yang diukur setiap hari.

\section{Analisis Data}

Penelitian ini menggunakan metode eksperimental dengan Rancangan Acak Lengkap (RAL). Penelitian ini menggunakan 4 macam perlakuan dengan 5 kali ulangan dengan satu faktor pembeda yaitu pemberian probiotik. Parameter yang diamati adalah kualitas air (amonia, nitrit dan nitrat). Data penelitian dianalisis menggunakan Analysis of Varian (ANOVA) dan dilanjutkan dengan uji lanjutan dengan menggunakan Uji Jarak Berganda Duncan (Duncan's Multiple Range Test) untuk mengetahui perbedaan antara perlakuan yang satu dengan perlakuan yang lainnya (Kusriningrum, 2012). Perhitungan statistik menggunakan aplikasi SPSS versi 16.

\section{HASIL DAN PEMBAHASAN}

Konsentrasi Amonia ( $\left.\mathrm{NH}_{3}\right)$

Berdasarkan hasil penelitian didapatkan konsentrasi amonia selama 30 hari berkisar antara 0,204-0,273 mg/L. Hasil uji statistic menunjukkan bahwa perlakuan pemberian probiotik berbeda dalam sistem akuaponik berbeda nyata $(p<0,05)$. Konsentrasi amonia terendah yaitu sebesar 0,204 $\mathrm{mg} / \mathrm{L}$ yaitu pada perlakuan P2 sedangkan konsentrasi amonia tertinggi yaitu sebesar $0,273 \mathrm{mg} / \mathrm{L}$ yaitu pada perlakuan P0 (kontrol). Hasil perhitungan Analisis of Varian (ANOVA) menunjukkan adanya perbedaan yang nyata $(\mathrm{p}<0,05)$ antara perlakuan P2 dengan perlakuan P0 (kontrol), tetapi perlakuan P1 tidak berbeda nyata dengan perlakuan P3. Data rata-rata konsentrasi amonia selama penelitian dapat dilihat pada Tabel 1. 
Tabel 1. Data Rata-rata Konsetrasi Amonia

\begin{tabular}{cc}
\hline Perlakuan & Konsentrasi Amonia (mg/l) \\
\hline P0 & $0,273^{\mathrm{c}} \pm 0,030$ \\
P1 & $0,239^{\mathrm{b}} \pm 0,028$ \\
P2 & $0,204^{\mathrm{a}} \pm 0,016$ \\
P3 & $0,237^{\mathrm{b}} \pm 0,004$
\end{tabular}

Keterangan : P0 (Kontrol), P1 (Probiotik A 0,25 $\mathrm{ml} / \mathrm{L}$ ), P2 (Probiotik B 0,25 ml/L), P3 (Probiotik C $0,25 \mathrm{ml} / \mathrm{L}$ ). Superskrip yang berbeda pada kolom yang sama menunjukkan terdapat perbedaan yang nyata $(\mathrm{p}<0,05)$

Pada perlakuan P2 didapatkan hasil terendah karena ditambahkan probiotik B yang berisi bakteri Lactobacillus, Bacillus, Nitrosomonas. Bakteri dalam probiotik tersebut bekerja efektif dalam menguraikan amonia sehingga kadar amonia rendah. Bakteri yang berperan penting dalam penguraian amonia menjadi nitrit adalah Nitrosomonas (Tambunan, 2010). Menurut Lisna dan Insulistyowati (2015), penambahan probiotik yang mengandung bakteri Nitrosomonas kedalam kolam pemeliharaan ikan dapat membantu penguraian bahan organik sehingga konsentrasi amonia menjadi lebih rendah bila dibandingkan dengan perlakuan P0 (kontrol).

Kadar amonia P0 (kontrol) sebesar 0,273 $\mathrm{mg} / \mathrm{L}$. Hal tersebut disebabkan karena pada perlakuan P0 (kontrol) tidak ditambahkan probiotik dalam media pemeliharaan, sehingga pemanfaatan bakteri pengurai amonia hanya berasal dari bakteri alami. Selain itu pada perlakuan P0 (kontrol), amonia tinggi karena disebabkan adanya penumpukan amonia akibat sisa pakan dan sisa metabolisme ikan yang menumpuk dan tidak terdekomposisi oleh bakteri pengurai (Irianto, 2003).

\section{Konsentrasi Nitrit ( $\left.\mathrm{NO}_{2}\right)$}

Berdasarkan hasil penelitian didapatkan konsentrasi nitrit selama 30 hari berkisar antara 0,012-0,019 $\mathrm{mg} / \mathrm{L}$. Penghitungan kadar nitrit dilakukan dengan metode spektrofotometri. Hasil uji statistic menunjukkan bahwa perlakuan pemberian probiotik berbeda dalam sistem akuaponik berbeda nyata $(\mathrm{p}<0,05)$. Setelah dilakukan Uji Jarak Berganda Duncan dapat diketahui bahwa konsentrasi nitrit tertinggi adalah pada perlakuan P0 (kontrol) yaitu sebesar 0,019 $\mathrm{mg} / \mathrm{L}$ dan konsentrasi nitrit terendah pada perlakuan P2 yaitu sebesar 0,012 $\mathrm{mg} / \mathrm{L}$. Data rata-rata konsentrasi nitrit selama penelitian dapat dilihat pada Tabel 2.

Tabel 2. Data Rata-rata Konsetrasi Nitrit

\begin{tabular}{cc}
\hline Perlakuan & Konsentrasi Nitrit $(\mathbf{m g} / \mathbf{l})$ \\
\hline P0 & $0,019^{\mathrm{c}} \pm 0,0007$ \\
P1 & $0,018^{\mathrm{b}} \pm 0,0007$ \\
P2 & $0,012^{\mathrm{a}} \pm 0,0000$ \\
P3 & $0,017^{\mathrm{b}} \pm 0,0004$ \\
\hline
\end{tabular}

Keterangan : P0 (Kontrol), P1 (Probiotik A 0,25 $\mathrm{ml} / \mathrm{L}$ ), P2 (Probiotik B 0,25 ml/L), P3 (Probiotik C $0,25 \mathrm{ml} / \mathrm{L}$ ). Superskrip yang berbeda pada kolom yang sama menunjukkan terdapat perbedaan yang nyata $(\mathrm{p}<0,05)$

Tingginya konsentrasi nitrit pada perlakuan P0 (kontrol) diduga karena bakteri alami untuk menguraikan dan memanfaatkan nitrit jumlahnya sedikit. Namun kandungan nitrit pada perlakuan P0 (kontrol) masih dalam batas normal. 
Menurut BBPBAT (2005), ambang batas nitrit adalah $<0,05 \mathrm{mg} / \mathrm{L}$. Senyawa nitrit yang berlebih dalam suatu perairan akan menyebabkan menurunnya kemampuan darah ikan untuk mengikat oksigen $\left(0_{2}\right)$, karena nitrit akan bereaksi lebih kuat dengan hemoglobin yang menyebabkan tingginya angka kematian (Samsundari dan Wirawan, 2013). Konsentrasi nitrit terendah pada perlakuan P2 disebabkan karena bakteri dalam probiotik B mampu memanfaatkan nitrit sebagai sumber energi untuk pertumbuhannya. Probiotik B berisi bakteri Lactobacillus, Bacillus dan Nitrosomonas. Menurut Pitrianingsih dkk. (2014) bakteri Bacillus yang ditambahkan pada media pemeliharaan berfungsi untuk merombak bahan organik melalui proses nitrifikasi membentuk nitrat.

\section{Konsentrasi Nitrat $\left(\mathrm{NO}_{3}\right)$}

Berdasarkan hasil penelitian didapatkan konsentrasi nitrat selama 30 hari berkisar antara 2,731-4,218 mg/L. Hasil uji statistic menunjukkan bahwa perlakuan pemberian probiotik berbeda dalam sistem akuaponik berbeda nyata $(\mathrm{p}<0,05)$. Konsentrasi nitrat terendah yaitu sebesar 2,731 $\mathrm{mg} / \mathrm{L}$ yaitu pada perlakuan P2 sedangkan konsentrasi nitrat tertinggi yaitu sebesar 4,218 mg/L yaitu pada perlakuan P0 (kontrol). Hasil perhitungan Analisis of Varian (ANOVA) menunjukkan adanya perbedaan yang nyata $(\mathrm{p}<0,05)$ antara perlakuan $\mathrm{P} 2$ dengan perlakuan $\mathrm{P} 0, \mathrm{P} 1$ dan P3. Data rata-rata konsentrasi nitrat selama penelitian dapat dilihat pada Tabel 3.

Tabel 3. Data Rata-rata Konsetrasi Nitrat

\begin{tabular}{cc}
\hline Perlakuan & Konsentrasi Nitrat $(\mathbf{m g} / \mathbf{l})$ \\
\hline P0 & $4,218^{\mathrm{d}} \pm 0,004$ \\
P1 & $3,949^{\mathrm{c}} \pm 0,009$ \\
P2 & $2,731^{\mathrm{a}} \pm 0,017$ \\
P3 & $3,239^{\mathrm{b}} \pm 0,018$ \\
\hline
\end{tabular}

Keterangan : P0 (Kontrol), P1 (Probiotik A 0,25 $\mathrm{ml} / \mathrm{L}$ ), P2 (Probiotik B 0,25 ml/L), P3 (Probiotik C $0,25 \mathrm{ml} / \mathrm{L}$ ). Superskrip yang berbeda pada kolom yang sama menunjukkan terdapat perbedaan yang nyata $(\mathrm{p}<0,05)$

Kadar nitrat tertinggi terdapat pada perlakuan P0 yaitu sebesar 4,218 mg/L. Namun kadar nitrat tersebut masih dalam batas normal untuk ikan lele yaitu $<5 \mathrm{mg} / \mathrm{L}$ (BBPBAT, 2005). Hal tersebut diduga karena penyerapan tanaman kangkung terhadap nitrat kurang optimal sehingga kadar nitrat pada perlakuan P0 cenderung tinggi. Dugaan kedua mungkin disebabkan karena adanya kadar amonia yang terlalu tinggi sehingga menyebabkan penyerapan tanaman kangkung tidak optimal. Hal tersebut sesuai dengan pernyataan Dauhan dkk. (2014) bahwa konsentrasi amonia yang terlalu tinggi mempengaruhi kemampuan tanaman kangkung untuk menyerap nitrat.

Kadar nitrat terendah terdapat pada perlakuan P2 dengan konsentrasi 2,731 mg/L. Hal tersebut membuktikan bahwa pada perlakuan P2 (probiotik B) bakteri bekerja secara efektif dalam menguraikan amonia sehingga nitrat dapat diserap oleh 
tanaman. Tanaman kangkung pada perlakuan P2 terlihat tumbuh secara optimal, hal tersebut membuktikan bahwa tanaman menyerap nitrat untuk pertumbuhannya. Namun batas ambang nitrat pada perlakuan P0 (kontrol) 4,218 mg/L masih dalam kadar aman untuk pemeliharaan ikan lele, karena batas ambang nitrat di perairan adalah $<5 \mathrm{mg} / \mathrm{L}$ (BBPBAT, 2005).

\section{Suhu, pH dan DO (Dissolved Oxygen)}

Tabel 4. Kisaran Suhu, pH dan DO (Dissolved Oxygen)

\begin{tabular}{cccc}
\hline Perlakuan & \multicolumn{3}{c}{ Parameter } \\
& Suhu $\left({ }^{\mathbf{}} \mathbf{C}\right)$ & $\mathbf{p H}$ & DO $(\mathbf{m g} / \mathbf{L})$ \\
\hline P0 & $28-30$ & $7,0-8,0$ & $4,16-5,17$ \\
P1 & $28-30$ & $7,2-8,0$ & $4,17-5,31$ \\
P2 & $28-30$ & $7,1-8,0$ & $4,20-5,81$ \\
P3 & $28-30$ & $7,3-8,1$ & $4,17-5,41$
\end{tabular}

Suhu merupakan parameter lingkungan yang sangat besar pengaruhnya pada hewan akuatik. Suhu merupakan faktor penting dan sangat berpengaruh pada kelangsungan hidup dan pertumbuhan ikan (Lisna dan Insulistyowati, 2015). Hasil pengukuran suhu selama penelitian pada semua perlakuan berkisar antara $28-30^{\circ} \mathrm{C}$. Kisaran suhu air ini masih dalam kisaran yang layak untuk pemeliharaan ikan lele yaitu berkisar antara $22-32^{\circ} \mathrm{C}$ (BBPBAT, 2005). Menurut Effendi (2003), peningkatan suhu air dapat menyebabkan terjadinya peningkatan dekomposisi bahan organik oleh bakteri.
Berdasarkan hasil pengukuran $\mathrm{pH}$ selama 30 hari didapatkan hasil berkisar antara 7,0-8,1. Hasil pengukuran $\mathrm{pH}$ tertinggi terdapat pada perlakuan P3 yang berkisar antara 7,3-8,1 dan $\mathrm{pH}$ terendah terdapat pada perlakuan P0 (kontrol). pH berada dibawah 6 atau lebih tinggi diatas 9 dapat menurunkan kemampuan reproduksi dan pertumbuhan ikan. Dengan demikian nilai $\mathrm{pH}$ (derajat keasaman) air masih dalam kisaran optimal hingga akhir penelitian karena kisaran $\mathrm{pH}$ untuk ikan lele yaitu berkisar antara 6-9 (BBPBAT, 2005). Hasil pengukuran kadar oksigen terlarut (DO) pada semua perlakuan berkisar antara 4,16 - 5,81 $\mathrm{mg} / \mathrm{L}$. Kandungan oksigen terlarut (DO) tertinggi terdapat pada perlakuan P2 (probiotik B) yaitu berkisar antara 4,20 - 5,81 $\mathrm{mg} / \mathrm{L}$ dan terendah berkisar antara 4,16 - 5,17 mg/L. Kandungan oksigen terlarut dalam semua perlakuan berfluktuasi namun masih dalam kisaran normal yaitu $>3 \mathrm{mg} / \mathrm{L}$. Apabila kadar DO dalam perairan rendah dapat berakibat terhadap pertumbuhan dan penurunan nafsu makan ikan (Samsundari dan Wirawan, 2013).

\section{KESIMPULAN DAN SARAN}

Kesimpulan yang diperoleh dari penelitian ini adalah pemberian probiotik dalam sistem akuaponik berpengaruh nyata $(\mathrm{p}<0,05)$ terhadap produksi kadar amonia, nitrit dan nitrat dengan produksi terendah 
pada perlakuan P2 (probiotik B) yang berisi bakteri Lactobacillus, Nitrosomonas dan Bacillus. Dengan kadar amonia 0,204 $\mathrm{mg} / \mathrm{L}$, nitrit $0,012 \mathrm{mg} / \mathrm{L}$ dan nitrat 2,731 mg/L. Probiotik komersil terbaik yang berpengaruh terhadap penurunan kadar amonia, nitrit dan nitrat adalah probiotik komersil B yang berisi bakteri bakteri Lactobacillus, Nitrosomonas dan Bacillus dengan penggunaan dosis $0,25 \mathrm{ml} / \mathrm{L}$.

Berdasarkan hasil penelitian yang telah dilakukan, pemberian probiotik komersil B (Lactobacillus, Nitrosomonas dan Bacillus) terbukti dapat menurunkan kadar amonia, nitrit dan nitrat dalam perairan, sehingga probiotik komersil B dapat digunakan pada budidaya ikan lele (Clarias sp.) dalam sistem akuaponik dengan harapan dapat mengurangi tingkat konsumsi air dan dapat digunakan untuk meningkatkan produksi budidaya. Dapat dilakukan penelitian selanjutnya tentang pemberian dosis yang berbeda guna mencari dosis yang tepat.

\section{DAFTAR PUSTAKA}

Ahmad, R. Z. 2007. Pemanfaatan Khamir Saccharomyces cerevisiae untuk Ternak. Balai Penelitian Veteriner. Bogor. 7 hal.

Aquarista, F., iskandar dan U. Subhan. 2012. Pemberian Probiotik dengan Carrier Zeolit pada Pembesaran Ikan Lele Dumbo (Clarias gariepinus). Fakultas Perikanan dan Ilmu
Kelautan. Universitas Padjajaran. Bandung. 8 hal.

Balai Besar Pengembangan Budidaya Air Tawar (BBPBAT). 2005. Petunjuk Pembenihan Ikan Lele Sangkuriang Clarias sp. Sukabumi.

Dauhan, R. E. S., E. Efendi dan Suparmono. 2014. Efekitvitas Sistem Akuaponik dalam Mereduksi Konsentrasi Amonia pada Sistem Budidaya Ikan. Fakultas Perikanan dan Kelautan. Universitas Lampung. 6 hal.

Direktorat Jenderal Perikanan Budidaya. 2014. Yogyakarta. Konsumsi Lele Tertinggi.http://www.wpi.kkp.go.id/? $\mathrm{p}=187$. Diakses tanggal 20 Februari 2015.

Diver, S. 2006. Aquaponics Integration of Hydroponics with Aquaculture. National Sustainable Agriculture Information Service, Australia.

Effendi, H. 2003. Telaah Kualitas Air Bagi Pengelola Sumberdaya Dan Lingkungan Perairan. Kanisius. hal 55-58.

Harahap, S. T., Mulyadi dan Rusliadi. 2010. Pemeliharaan Benih Ikan Baung (Mystus nemurus) dengan Sistem Bioflok pada Sistem Resirkulasi Akuaponik. Fakultas Perikanan dan Kelautan. Universitas Riau. 7 hal.

Irianto, A. 2003. Probiotik Akuakultur. Cetakan I. Penerbit Gadjah Mada University Press. Bulaksumur. Yogyakarta. 125 hal.

Kusriningrum, R. S. 2012. Buku Ajar Perancangan Percobaan. Cetakan Keempat. Dani Abadi. Surabaya. hal 6-18. 
Lisna dan Insulistyowati. 2015. Potensi Mikroba Probiotik_FM dalam Meningkatkan Kualitas Air Kolam dan Laju Pertumbuhan Benih Ikan Lele Dumbo (Clarias gariepinus). Fakultas Peternakan. Universitas Jambi.Mendalo. 8 hal.

Mahyuddin. 2008. Panduan Lengkap Agribisnis Lele. Penebar Swadaya. Jakarta. hal 171.

Pitrianingsih, C., Suminto dan Sarjito. 2014. Pengaruh Kandidat Probiotik Terhadap Perubahan Kandungan Nutrien C,N,P dan K Melalui Kultur Lele Dumbo (Clarias gariepinus). Fakultas Perikanan dan Ilmu
Kelautan. Universitas Diponegoro. Semarang. 10 hal.

Samsundari, S. dan G. A. Wirawan. 2013. Analisis Penerapan Biofilter dalam Sistem Resirkulasi Terhadap Mutu Kualitas Air Budidaya Ikan Sidat (Anguilla bicolor). Fakultas Pertanian dan Peternakan. Universitas Muhammadiyah Malang. Malang. 12 hal.

Tambunan, E. P., U. M. Tang dan Mulyadi. 2010. Cultivation of River Catfish (Mystus nemurus) in Aquaponic Resirculation System With The Addition of EM4. Fakultas Perikanan dan Imu Kelautan Universitas Riau. 6 hal. 